Review

\title{
Role of Natural Killer and Gamma-Delta T Cells in West Nile Virus Infection
}

\section{Tian Wang ${ }^{1,2, *}$ and Thomas Welte ${ }^{1}$}

1 Department of Microbiology and Immunology, University of Texas Medical Branch, Galveston, TX 77555, USA; E-Mail: thomaswelte2007@gmail.com

2 Department of Pathology, Sealy Center for Vaccine Development, Center for Biodefense and Emerging Infectious Diseases, and Institute for Human Infections and Immunity, University of Texas Medical Branch, Galveston, TX 77555, USA

* Author to whom correspondence should be addressed; E-Mail: ti1wang@utmb.edu; Tel.: +1-409-772-3146; Fax: +1-409-772-3338.

Received: 25 July 2013; in revised form: 30 August 2013 / Accepted: 16 September 2013 / Published: 20 September 2013

\begin{abstract}
Natural Killer (NK) cells and Gamma-delta T cells are both innate lymphocytes that respond rapidly and non-specifically to viral infection and other pathogens. They are also known to form a unique link between innate and adaptive immunity. Although they have similar immune features and effector functions, accumulating evidence in mice and humans suggest these two cell types have distinct roles in the control of infection by West Nile virus (WNV), a re-emerging pathogen that has caused fatal encephalitis in North America over the past decade. This review will discuss recent studies on these two cell types in protective immunity and viral pathogenesis during WNV infection.
\end{abstract}

Keywords: West Nile virus; Natural Killer cells; Gamma-delta T cells

\section{Introduction}

West Nile virus (WNV), a plus-sense, single-stranded neurotropic flavivirus, has been a public health concern in North America for more than a decade [1,2]. The virus is maintained in an enzootic cycle that involves mosquitoes and birds, with humans and horses as incidental hosts. Infection in humans results from mosquito bites, blood transfusion, organ transplantation, breast feeding, and in utero or occupational exposure [2-6]. WNV infection of the central nervous system (CNS, neuroinvasive disease) commonly 
presents as encephalitis, meningitis, or acute flaccid paralysis. The overall mortality rate in persons who develop WNV neuroinvasive disease is about $10 \%$, although the mortality rate increases significantly in the elderly and immunocompromised. Recently, some WNV convalescent patients were reported to have significant long-term morbidity years after their acute illness; symptoms include muscle weakness and pain, fatigue, memory loss, and ataxia [7-11]. At present, there is no specific therapeutic agent for treatment of the infection. No approved human vaccines are available for its prevention.

WNV has been studied in various animal models, including mice, hamsters, monkeys, and horses [12-15]. The murine model is an effective in vivo experimental model to investigate viral pathogenesis and host immunity in humans. Following the initial subcutaneous or intraperitoneal inoculation in mice, WNV induces a systemic infection and eventually invades the CNS. Mice die rapidly when encephalitis develops, usually within one to two weeks. The severity and symptoms of lethal infection observed in the murine model mimic the symptoms caused by WNV infection in humans $[13,16,17]$. Studies from experimental animal models, in vitro cell culture, and/or WNV patient samples have provided important insights into host immunity to WNV infection. Natural killer (NK) cells and $\gamma \delta \mathrm{T}$ cells are two innate lymphocytes that respond rapidly and non-specifically to viral infection. They are also known to form a unique link between innate and adaptive immunity. Moreover, the characteristics of these two cell types in adaptive immunity have been described in several disease models [18-21]. In this review, we will discuss recent studies on these two unique cell types in both protective immunity and viral pathogenesis during WNV infection.

\section{NK Cells}

NK cells are important for early immune reactions against viral infections and cancer. They are a subset of lymphocytes that provide innate effector mechanisms through secretion of cytokines and direct cytotoxic effects, which are triggered by releasing cytotoxic granules containing perforin and granzymes [22].

\subsection{NK Cells in Host Immunity to WNV Infection}

NK cells have been reported to be involved in the host immunity to infection of many flaviviruses, including yellow fever virus, Japanese encephalitis virus, tick-borne encephalitis virus, dengue virus, and WNV [23-26]. Vargin et al. [25] were the first to report that infection of mice with WNV was accompanied by the temporary activation of NK cells in the spleen. Similar to other innate immune cells, such as monocytes and dendritic cells (DCs), NK cells can migrate into the CNS as the virus invades the brain, following a systemic infection in mice [27]. They presumably play an important role in the control of WNV infection by their recognition and elimination of infected cells, as demonstrated in ex vivo cytotoxicity assays reported by several groups. In one study [28], brain leukocytes isolated from WNV-infected mice displayed an NK cell phenotype and had the ability to lyse WNV-infected and non-infected cell lines in vitro. Another group showed that active human NK cells, which resulted from co-cultivation of peripheral blood mononuclear cells (PMBCs) with radiation-killed K562-mb15-41BBL stimulatory cells inhibited WNV infection in Vero cells [29].

There are also conflicting reports about the functional significance of NK cells in WNV-infected hosts. For example, WNV-infected mouse astrocytes were shown to be resistant to NK cell lysis, 
which was indicative of a low susceptibility of CNS cells to NK cells during WNV infection [30]. When NK cells were depleted in mice by using an antibody against NK1.1, the mice neither became more susceptible to WNV nor was there an increased morbidity. Furthermore, the Ly49a transgenic strain of mice, which is deficient in circulating NK cells, also showed a susceptibility to WNV similar to that of wild-type mice [31]. Thus, the role of NK cells during in vivo WNV infection remains controversial. There are a few possible reasons to explain this complexity. First, the divergent phenotypic and functional features of NK cells are often influenced by organ-specific factors, including local microenvironment and unique cellular interactions [32]. This has been well documented in several disease models. During coronavirus infection or in autoimmune disease, CNS-specific NK cells provided protection against encephalitis, either by reducing viral replication or inhibiting the activation of autoimmune $\mathrm{T}$ cells through killing of activated microglia [33,34]; whereas during chronic hepatitis $\mathrm{C}$ virus infection, hepatic NK cells were found to inhibit liver fibrosis and tissue regeneration by promoting stellate cell death [35]. Likewise, the CNS-specific NK cells may have distinct functions during in vivo infection other than direct killing of WNV-infected local cells. Interestingly, a recent study [36] showed that NK cells were capable of preventing the spread of WNV infection only to certain mouse tissues, such as the liver, but not the spleen. Additionally, WNV could develop strategies in evasion of NK-cell mediated killing during in vivo infection. NK cell activation is regulated by the balance of activating and inhibitory receptors on its surface. The inhibitory receptors killer cell immunoglobulin-like (KIR) receptors in humans, the lectin-like Ly49 (mouse), and the CD94-NKG2A dimers bind to major histocompatibility complex (MHC) class I molecules. Infection of mouse or human cells with flaviviruses is known to increase the cell-surface expression of MHC class I [37,38]. In particular, WNV infection upregulates MHC class I expression by enhancing the transport activity of TAP and by NF- $\kappa \mathrm{B}-$ dependent transcription activation of MHC class I genes [39-41]. Therefore, WNV may evade NK-cell mediated killing by upregulation of MHC class I on infected cells. Lastly, although the depletion approach has been commonly used to determine the functional role of NK cells during in vivo flavivirus infection [31,42], it has been reported that NK cells can't be fully depleted in all WNV-infected tissues [36].

\subsection{Factors that Contribute to NK Cell-Activation and Killing during WNV Infection}

Activated NK cells inhibited WNV infection of Vero cells through both antibody-dependent cellular cytotoxicity (ADCC) and non-cytolytic activities, such as secretion of interferon (IFN)- $\gamma$ [29]. Both host factors and microbial signals are involved in triggering NK cell activation during viral infection. NK cells can detect microbial signals by stimulation of their pathogen recognition receptors (PRRs), such as toll-like receptor (TLR) or RIG-I like receptor (RLR), or being activated by innate cytokines predominantly produced by infected DCs $[43,44]$. By using the integrated system biology approach, Suthar et al. [36] have recently demonstrated that the liver-specific NK cell activation during WNV infection is regulated by two innate immune signaling pathways, including RLR and IFN. In WNV-infected liver, IFN functions intrinsically in regulation of NK cell activation, proliferation, and maturation; whereas RLR-mediated type 1 IFN production in DCs imparts signaling extrinsically via crosstalk to NK cells and triggers their activation. NK cells are also known to sense microbial and non-microbial signals from target cells through a variety of activating and inhibitory receptors, which 
influence cytotoxicity towards virus-infected cells and cancerous cells [45]. Upon WNV infection, interaction of the activating receptor NKp44 of human NK cells with domain III of the WNV envelope (E) protein was shown to be an important step in triggering both IFN- $\gamma$ secretion and cytolytic activity of NK cells during infection [46].

\section{3. $\gamma \delta$ T Cells}

$\gamma \delta \mathrm{T}$ cells comprise a minority of the $\mathrm{CD}^{+} \mathrm{T}$ cells in lymphoid tissue and blood, but are well represented at epithelial and mucosal sites [47]. Unlike $\alpha \beta \mathrm{T}$ cells, they lack MHC restriction and have the potential capacity to respond to antigens without a requirement for conventional antigen processing [48]. In response to microbial antigens, $\gamma \delta$ T cells can rapidly produce cytokines, such as IFN- $\gamma$, tumor necrosis factor (TNF)- $\alpha$ and interleukin (IL)-17 [49,50]. $\gamma \delta \mathrm{T}$ cells are divisible into functionally distinct subsets, which distribute in an organ-specific manner. In mice, $\gamma \delta \mathrm{T}$ cells include mostly $\mathrm{V} \gamma 1, \mathrm{~V} \gamma 2$, $\mathrm{V} \gamma 4, \mathrm{~V} \gamma 5, \mathrm{~V} \gamma 6$, and $\mathrm{V} \gamma 7$ subsets [51], which have direct and indirect effects on host immunity to many infectious pathogens [52,53].

\subsection{The Protective Effects of $\gamma \delta T$ Cells in Innate and Adaptive Immunity against WNV}

$\gamma \delta \mathrm{T}$ cells are important for protective immunity against WNV infection. $\mathrm{TCR} \delta^{-/}$mice, which are deficient in $\gamma \delta$ T cells, had elevated viremia, as well as more severe encephalitis, and were much more susceptible to WNV infection than were the wild-type controls [54]. The IFN- $\gamma$ producing activity partially contributes to their protective effect in host immunity (Table 1). Upon WNV infection, $\gamma \delta \mathrm{T}$ cells quickly expanded as early as day two and are the major resource for producing IFN- $\gamma$. Furthermore, transfer of splenocytes from $\mathrm{TCR} \beta^{-/-} \mathrm{IFN} \gamma^{-/-}$mice, which have a defect in the IFN- $\gamma$-producing capacity of $\gamma \delta \mathrm{T}$ cells, did not affect host susceptibility in $\mathrm{TCR} \delta^{-/-}$mice [54]. Another group also demonstrated that irradiated mice reconstituted with IFN- $\gamma$-deficient $\gamma \delta \mathrm{T}$ cells had significantly higher levels of viral loads in the blood and brains during WNV infection than mice reconstituted with IFN- $\gamma$-sufficient $\gamma \delta \mathrm{T}$ cells [55]. $\mathrm{V} \gamma 1^{+}$cells were the major $\gamma \delta$ subset producing IFN- $\gamma$. Mice depleted of $\mathrm{V} \gamma 1^{+}$cells displayed a phenotype similar to that observed in $\mathrm{TCR} \delta^{-/}$mice in response to $\mathrm{WNV}$ infection ([56], Table 1). Cytolytic function is another important mechanism of viral control attributed to $\gamma \delta \mathrm{T}$ cells [57-59]. TCR $\delta^{-/-}$mice had reduced levels of intracellular perforin in splenocytes at day six, post-WNV infection, implying their contribution to cytolytic activity (Table 1) [54]. Both CD4 ${ }^{+}$ and $\mathrm{CD}^{+} \mathrm{T}$ cells have been shown to be responsible for the cytolytic activity detected in splenocytes during the first week of WNV infection $[60,61]$. We have noted that splenic $\mathrm{CD} 4^{+} \mathrm{T}$ cells of $\mathrm{TCR} \delta^{-/}$ mice had a lower cytotoxicity potential than those of wild-type mice [62]. Thus, $\gamma \delta \mathrm{T}$ cells may contribute to the cytolytic activity against WNV in the periphery directly and/or indirectly by regulation of $\alpha \beta$ T cell response.

$\gamma \delta \mathrm{T}$ cells also play a role in memory $\mathrm{T}$ cell development during $\mathrm{WNV}$ infection. $\mathrm{TCR} \delta^{--}$mice that survived primary WNV infection had a numeric and functional reduction in memory $\mathrm{T}$ cell responses. However, $\gamma \delta \mathrm{T}$ cells are not directly involved in the recall response to WNV infection. This is supported by the fact that depletion of these cells in WNV-infected mice does not affect host susceptibility to the secondary challenge [63]. In WNV-infected $\mathrm{TCR} \delta^{-/-}$mice, splenic DCs had an impaired antigen-presenting capacity, and lower levels of CD40, CD80, CD86, and MHC class II 
expression and IL-12 production than did those of wild-type mice [64]. This suggests that the crosstalk between $\gamma \delta$ T cells and DCs plays an important role in promoting DC maturation and T cell priming. A low level of WNV replication in $\gamma \delta$ T cells induced pro-inflammatory cytokines, including IFN- $\gamma$, and TNF- $\alpha$ (Table 1). DCs co-cultured with WNV-infected $\gamma \delta \mathrm{T}$ cells also had enhanced levels of co-stimulatory molecules, MHC class II expression, and IL-12 production [64]. Thus, WNV-activated $\gamma \delta$ T cells promote DC activation through direct contact with DCs and/or the secreting molecules induced upon infection.

Table 1. $\gamma \delta$ T cells in host immunity to West Nile virus (WNV) infection.

\begin{tabular}{|c|c|c|}
\hline Functionality & Role in host immunity & Major $\gamma \delta$ subsets involved \\
\hline CTL activity & Control of WNV dissemination & ? detected within the first week \\
\hline Production of IFN- $\gamma$ & Control of WNV dissemination; Promote DC maturation & $\mathrm{V} \gamma 1^{+}$cells, as early as day 2 \\
\hline Production of TNF- $\alpha$ & $\begin{array}{l}\text { Promote DC maturation and activation; Contribute to } \\
\text { BBB compromise and increase viral load in the CNS }\end{array}$ & $\mathrm{V} \gamma 4^{+}$cells \\
\hline Production of IL-17 & Not known & $\mathrm{V} \gamma 4^{+}$cells \\
\hline Production of IL-10 & $\begin{array}{l}\text { Increase viral infection and mortality during WNV } \\
\text { infection }\end{array}$ & $\begin{array}{l}\text { Mostly by } \mathrm{CD}^{+} \alpha \beta \text { T cells and } \\
\text { suppressed by } \mathrm{V} \gamma 1^{+} \text {cells }\end{array}$ \\
\hline Production of TGF- $\beta$ & $\begin{array}{l}\text { Suppress } \mathrm{V} \gamma 1^{+} \text {cell expansion in the periphery and } \\
\text { their infiltration into the CNS }\end{array}$ & $\mathrm{V} \gamma 4^{+}$cells \\
\hline Anti-inflammation & Reduce inflammation in the CNS & $\mathrm{V} \gamma 1^{+}$cells \\
\hline
\end{tabular}

\section{2. $\gamma \delta T$ Cells in WNV Pathogenesis}

A major risk factor for fatality due to WNV infection in humans is aging $[65,66]$. Aged mice were more susceptible to WNV infection than young adult mice [56,67]. $\mathrm{V} \gamma 1^{+}$cells of aged mice displayed a slower, reduced response to WNV infection compared to those of young adult mice, suggesting dysfunction of $\gamma \delta \mathrm{T}$ cells contribute to host susceptibility to WNV encephalitis [56]. Immunotherapy can improve the anti-tumor effect of $\gamma \delta \mathrm{T}$ cells [68,69]. In one study [70], oral administration of active hexose correlated compound (AHCC), an extract of Lentinula edodes of the Basidiomycete family of fungi rich in $\alpha$-glucans, enhanced the protective $\mathrm{V} \gamma 1^{+} \mathrm{T}$ cell response and thus attenuated viremia in aged mice following lethal WNV infection.

Aged mice, when compared to young adult mice, also displayed a higher content of $\mathrm{V} \gamma 4^{+}$cells, another major subpopulation of peripheral $\gamma \delta \mathrm{T}$ cells. Depletion of $\mathrm{V} \gamma 4^{+}$cells in young mice resulted in a lower mortality following WNV-induced encephalitis [56]. The pathogenic effects of $\mathrm{V} \gamma 4^{+}$cells are mediated via the production of proinflammatory and regulatory cytokines during WNV infection $([56,71]$, see Table 1). TNF- $\alpha$ has been reported to be responsible for BBB compromise and WNV entry into the brain [72]. ${\mathrm{V} \gamma 4^{+}}^{+}$cell-depleted mice had reduced TNF- $\alpha$ levels in the CNS, accompanied by a

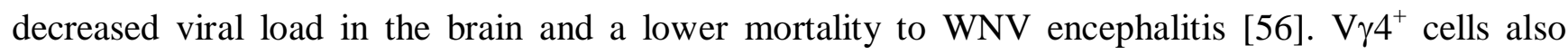
produced IL-17, which is known to increase inflammation by recruiting cells, such as neutrophils or macrophages, to infection sites in several disease models [73,74]. Nevertheless, the IL-17- producing activity is considered to be dispensable for host immunity against WNV, as in vivo blocking of IL-17

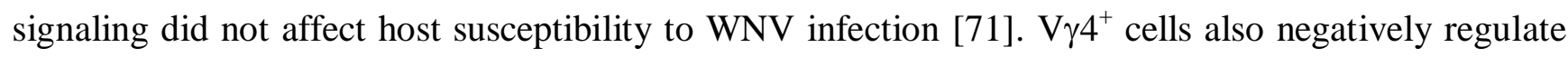
$\mathrm{V}_{\gamma} 1^{+} \mathrm{T}$ cell responses during WNV infection via the production of TGF- $\beta$ (Table 1). This effect contributes directly to higher viremia, which leads to more virus dissemination into the CNS, and 
induction of encephalitis [56,71]. Additionally, the suppressive effects of $\mathrm{V} \gamma 4^{+}$cells are associated with decreased IL-10 levels and reduced inflammation in the CNS ([71], Table 1). IL-10 plays a pathogenic role

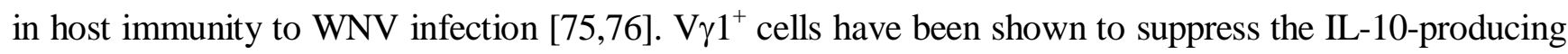
$\mathrm{CD} 4^{+} \mathrm{CD} 25^{+} \mathrm{T}$ cells in the lungs of ovalbumin-sensitized and challenged mice [77]. Moreover, $\mathrm{V} \gamma 1^{+} \mathrm{T}$ cells are known to decrease inflammation during bacterial and coxsackievirus infection [52,78].

\subsection{Factors that Contribute to $\gamma \delta$ T Cell Activation during WNV Infection}

There are few antigens reported to be recognized by $\gamma \delta \mathrm{T}$ cell receptors [79]. TLRs sense different pathogen-associated molecular patterns (PAMP) during microbial infection [80,81]. The expression of PRRs, such as TLR2, TLR3, TLR4, and TLR7/8, on $\gamma \delta \mathrm{T}$ cells has been reported [82-85]. Among them, TLR3- and TLR7-induced innate cytokine responses are involved in both protection and pathogenesis during WNV infection [72,86-88]. Myeloid differentiation factor 88 (MyD88), the primary adaptor for most TLRs, also restricts WNV by inhibiting replication in subsets of cells and modulating immune cell migration into the CNS [89]. We have recently found that $\gamma \delta \mathrm{T}$ cells of MyD88 and TLR -deficient mice, had a reduced expansion and activation compared to those of wild-type mice following WNV infection, which indicates a role of MyD88-dependent PRR signaling in $\gamma \delta \mathrm{T}$ cell activation [90]. TLRs are known to directly or indirectly contribute to $\gamma \delta \mathrm{T}$ cell activation. TLR ligands could act as co-stimulatory signals for TCR-activated human $\gamma \delta$ T cells [91,92]. Alternatively, $\gamma \delta$ T cells and DCs also exert regulatory influences on each other. For example, induction of human $\gamma \delta \mathrm{T}$ cells by poly I:C, a ligand for TLR3, depends on DCs mediated by Type-1 IFNs [93]. Human $\gamma \delta$ T cells were activated by plasmacytoid DCs upon infection by another important flavivivirus, yellow fever virus [94]. Whether $\gamma \delta \mathrm{T}$ cells are induced by WNV directly via their innate immune receptors, such as TLRs, or indirectly by interaction with TLR-expressing innate immune cells remains under investigation.

\section{Conclusions}

In summary, NK cells and $\gamma \delta \mathrm{T}$ cells play both similar and dissimilar roles in host immunity to WNV infection (Table 2). They both respond rapidly and non-specifically to WNV infection and control viral dissemination by secretion of IFN- $\gamma$ and/or cytolytic activity. Both cell types cross-talk with DCs during WNV infection, which results in DC maturation and NK cell activation [36,64]. PRR-mediated innate immune signaling pathways, including those used by TLR, RLR-, or IFN, are important for regulation of NK cell and $\gamma \delta \mathrm{T}$ cell activation during WNV infection. Furthermore, $\gamma \delta \mathrm{T}$ cells regulate memory $\mathrm{T}$ cell development by promoting DC maturation and activation. The role of NK cells in adaptive immunity to WNV infection remained undefined. $\gamma \delta \mathrm{T}$ cell subsets display distinct functions in both protection and pathogenesis upon WNV infection. The role of NK cells during in vivo WNV infection is complex and sometimes paradoxical. The functional significance of NK cells in WNV susceptibility should be investigated in an organ-specific manner, with a full characterization of multiple activating and inhibitory receptors on the NK cell surface. Due to their unique role in host innate and adaptive immunity, studies of the functionality of NK cells and $\gamma \delta \mathrm{T}$ cells and their cross-talk with DCs will provide important insights into WNV immunotherapy and vaccine development for the potential target population. 
Table 2. Comparison of Natural Killer (NK cells) and $\gamma \delta \mathrm{T}$ cells in host immunity to WNV infection.

\begin{tabular}{|c|c|c|}
\hline Category & NK cells & $\gamma \delta \mathrm{T}$ cells \\
\hline CTL & $\begin{array}{l}\text { Direct cytotoxicity, ADCC and IFN- } \gamma \\
\text { production }\end{array}$ & Direct cytotoxicity, and IFN- $\gamma$ production \\
\hline Cross-talk with DCs & Yes, this triggers NK cell activation & Yes, this leads to DC maturation \\
\hline $\begin{array}{l}\text { Role in Adaptive } \\
\text { Immunity }\end{array}$ & Not known & $\begin{array}{l}\text { Regulate } \mathrm{T} \text { cell response via promoting } \\
\mathrm{DC} \text { maturation and activation }\end{array}$ \\
\hline Subsets Diversity & Not known & $\begin{array}{l}\mathrm{V} \gamma 1 \text { and } \mathrm{V} \gamma 4 \text { subsets have distinct roles } \\
\text { in protection and pathogenesis }\end{array}$ \\
\hline Organ-specific function & $\begin{array}{l}\text { Yes, mouse liver and spleen NK cells have } \\
\text { different roles during WNV infection }\end{array}$ & Not known \\
\hline $\begin{array}{l}\text { Innate immune signaling } \\
\text { pathways involved }\end{array}$ & RIG-I, IFN & MyD88-dependent PRRs \\
\hline Host studied & Human, mouse & Mouse \\
\hline
\end{tabular}

\section{Acknowledgments}

NIH grants R01AI072060 and R03 AI079444 supported this work. We thank Mardelle Susman for help in the preparation of this manuscript.

\section{Conflicts of Interest}

The authors declare no conflict of interest.

\section{References and Notes}

1. Kramer, L.D.; Styer, L.M.; Ebel, G.D. A global perspective on the epidemiology of West Nile virus. Annu. Rev. Entomol. 2008, 53, 61-81.

2. Campbell, G.L.; Marfin, A.A.; Lanciotti, R.S.; Gubler, D.J. West Nile virus. Lancet Infect. Dis. 2002, 2, 519-529.

3. Centers for Disease Control and Prevention (CDC). Possible West Nile virus transmission to an infant through breast-feeding-Michigan, 2002. MMWR Morb. Mortal. Wkly. Rep. 2002, 51, 877-878.

4. Centers for Disease Control and Prevention (CDC). Laboratory-acquired West Nile virus infections-United States, 2002. MMWR Morb. Mortal. Wkly. Rep. 2002, 51, 1133-1135.

5. Alpert, S.G.; Fergerson, J.; Noel, L.P. Intrauterine West Nile virus: Ocular and systemic findings. Am. J. Ophthalmol. 2003, 136, 733-735.

6. Charatan, F. Organ transplants and blood transfusions may transmit West Nile virus. Br. Med. J. 2002, 325, PMCID:PMC1169473.

7. Carson, P.J.; Konewko, P.; Wold, K.S.; Mariani, P.; Goli, S.; Bergloff, P.; Crosby, R.D. Long-term clinical and neuropsychological outcomes of West Nile virus infection. Clin. Infect. Dis. 2006, 43, 723-730. 
8. Ravindra, K.V.; Freifeld, A.G.; Kalil, A.C.; Mercer, D.F.; Grant, W.J.; Botha, J.F.; Wrenshall, L.E.; Stevens, R.B. West Nile virus-associated encephalitis in recipients of renal and pancreas transplants: Case series and literature review. Clin. Infect. Dis. 2004, 38, 1257-1260.

9. Ou, A.C.; Ratard, R.C. One-year sequelae in patients with West Nile virus encephalitis and meningitis in Louisiana. J. La. State Med. Soc. 2005, 157, 42-46.

10. Cook, R.L.; Xu, X.; Yablonsky, E.J.; Sakata, N.; Tripp, J.H.; Hess, R.; Piazza, P.; Rinaldo, C.R. Demographic and clinical factors associated with persistent symptoms after West Nile virus infection. Am. J. Trop. Med. Hyg. 2010, 83, 1133-1136.

11. Sadek, J.R.; Pergam, S.A.; Harrington, J.A.; Echevarria, L.A.; Davis, L.E.; Goade, D.; Harnar, J.; Nofchissey, R.A.; Sewell, C.M.; Ettestad, P.; et al. Persistent neuropsychological impairment associated with West Nile virus infection. J. Clin. Exp. Neuropsychol. 2010, 32, 81-87.

12. Davis, B.S.; Chang, G.J.; Cropp, B.; Roehrig, J.T.; Martin, D.A.; Mitchell, C.J.; Bowen, R.; Bunning, M.L. West Nile virus recombinant DNA vaccine protects mouse and horse from virus challenge and expresses in vitro a noninfectious recombinant antigen that can be used in enzyme-linked immunosorbent assays. J. Virol. 2001, 75, 4040-4047.

13. Kramer, L.D.; Bernard, K.A. West Nile virus infection in birds and mammals. Ann. NY Acad. Sci. 2001, 951, 84-93.

14. Ratterree, M.S.; Gutierrez, R.A.; Travassos da Rosa, A.P.; Dille, B.J.; Beasley, D.W.; Bohm, R.P.; Desai, S.M.; Didier, P.J.; Bikenmeyer, L.G.; Dawson, G.J.; et al. Experimental infection of rhesus macaques with West Nile virus: Level and duration of viremia and kinetics of the antibody response after infection. J. Infect. Dis. 2004, 189, 669-676.

15. Xiao, S.Y.; Guzman, H.; Zhang, H.; Travassos da Rosa, A.P.; Tesh, R.B. West Nile virus infection in the golden hamster (Mesocricetus auratus): A model for West Nile encephalitis. Emerg. Infect. Dis. 2001, 7, 714-721.

16. Beasley, D.W.; Li, L.; Suderman, M.T.; Barrett, A.D. Mouse neuroinvasive phenotype of West Nile virus strains varies depending upon virus genotype. Virology 2002, 296, 17-23.

17. Wang, T.; Anderson, J.F.; Magnarelli, L.A.; Wong, S.J.; Koski, R.A.; Fikrig, E. Immunization of mice against West Nile virus with recombinant envelope protein. J. Immunol. 2001, 167, 5273-5277.

18. Sun, J.C.; Lanier, L.L. Natural killer cells remember: An evolutionary bridge between innate and adaptive immunity? Eur. J. Immunol. 2009, 39, 2059-2064.

19. Bonneville, M.; O’Brien, R.L.; Born, W.K. Gammadelta T cell effector functions: A blend of innate programming and acquired plasticity. Nat. Rev. Immunol. 2010, 10, 467-478.

20. Shen, Y.; Zhou, D.; Qiu, L.; Lai, X.; Simon, M.; Shen, L.; Kou, Z.; Wang, Q.; Jiang, L.; Estep, J.; et al. Adaptive immune response of Vgamma2Vdelta2+ $\mathrm{T}$ cells during mycobacterial infections. Science 2002, 295, 2255-2258.

21. Colonna, M.; Jonjic, S.; Watzl, C. Natural killer cells: Fighting viruses and much more. Nat. Immunol. 2011, 12, 107-110.

22. Vivier, E.; Tomasello, E.; Baratin, M.; Walzer, T.; Ugolini, S. Functions of natural killer cells. Nat. Immunol. 2008, 9, 503-510. 
23. Martins, M.A.; Silva, M.L.; Eloi-Santos, S.M.; Ribeiro, J.G.; Peruhype-Magalhaes, V.; Marciano, A.P.; Homma, A.; Kroon, E.G.; Teixeira-Carvalho, A.; Martins-Filho, O.A. Innate immunity phenotypic features point toward simultaneous raise of activation and modulation events following 17DD live attenuated yellow fever first-time vaccination. Vaccine 2008, 26, 1173-1184.

24. Sooryanarain, H.; Ayachit, V.; Gore, M. Activated CD56(+) lymphocytes (NK+NKT) mediate immunomodulatory and anti-viral effects during Japanese encephalitis virus infection of dendritic cells in vitro. Virology 2012, 432, 250-260.

25. Vargin, V.V.; Semenov, B.F. Changes of natural killer cell activity in different mouse lines by acute and asymptomatic flavivirus infections. Acta Virol. 1986, 30, 303-308.

26. Kurane, I.; Hebblewaite, D.; Brandt, W.E.; Ennis, F.A. Lysis of dengue virus-infected cells by natural cell-mediated cytotoxicity and antibody-dependent cell-mediated cytotoxicity. J. Virol. 1984, 52, 223-230.

27. Brehin, A.C.; Mouries, J.; Frenkiel, M.P.; Dadaglio, G.; Despres, P.; Lafon, M.; Couderc, T. Dynamics of immune cell recruitment during West Nile encephalitis and identification of a new CD19+B220-BST-2+ leukocyte population. J. Immunol. 2008, 180, 6760-6767.

28. Liu, Y.; Blanden, R.V.; Mullbacher, A. Identification of cytolytic lymphocytes in West Nile virus-infected murine central nervous system. J. Gen. Virol. 1989, 70, 565-573.

29. Zhang, M.; Daniel, S.; Huang, Y.; Chancey, C.; Huang, Q.; Lei, Y.F.; Grinev, A.; Mostowski, H.; Rios, M.; Dayton, A. Anti-West Nile virus activity of in vitro expanded human primary natural killer cells. BMC Immunol. 2010, 11, doi:10.1186/1471-2172-11-3.

30. Liu, Y.; Mullbacher, A. Astrocytes are not susceptible to lysis by natural killer cells. J. Neuroimmunol. 1988, 19, 101-110.

31. Shrestha, B.; Samuel, M.A.; Diamond, M.S. CD8+ T Cells require perforin to clear West Nile virus from infected neurons. J. Virol. 2006, 80, 119-129.

32. Shi, F.D.; Ljunggren, H.G.; la Cava, A.; van Kaer, L. Organ-specific features of natural killer cells. Nat. Rev. Immunol. 2011, 11, 658-671.

33. Trifilo, M.J.; Montalto-Morrison, C.; Stiles, L.N.; Hurst, K.R.; Hardison, J.L.; Manning, J.E.; Masters, P.S.; Lane, T.E. CXC chemokine ligand 10 controls viral infection in the central nervous system: evidence for a role in innate immune response through recruitment and activation of natural killer cells. J. Virol. 2004, 78, 585-594.

34. Hao, J.; Liu, R.; Piao, W.; Zhou, Q.; Vollmer, T.L.; Campagnolo, D.I.; Xiang, R.; la Cava, A.; van Kaer, L.; Shi, F.D. Central nervous system (CNS)-resident natural killer cells suppress Th17 responses and CNS autoimmune pathology. J. Exp. Med. 2010, 207, 1907-1921.

35. Krueger, P.D.; Lassen, M.G.; Qiao, H.; Hahn, Y.S. Regulation of NK cell repertoire and function in the liver. Crit. Rev. Immunol. 2011, 31, 43-52.

36. Suthar, M.S.; Brassil, M.M.; Blahnik, G.; McMillan, A.; Ramos, H.J.; Proll, S.C.; Belisle, S.E.; Katze, M.G.; Gale, M., Jr. A systems biology approach reveals that tissue tropism to West Nile virus is regulated by antiviral genes and innate immune cellular processes. PLoS Pathog. 2013, 9 , e1003168.

37. Lobigs, M.; Blanden, R.V.; Mullbacher, A. Flavivirus-induced up-regulation of MHC class I antigens; implications for the induction of CD8+ T-cell-mediated autoimmunity. Immunol. Rev. 1996, 152, 5-19. 
38. Ye, J.; Zhu, B.; Fu, Z.F.; Chen, H.; Cao, S. Immune evasion strategies of flaviviruses. Vaccine 2013, 31, 461-471.

39. Kesson, A.M.; Cheng, Y.; King, N.J. Regulation of immune recognition molecules by flavivirus, West Nile. Viral. Immunol. 2002, 15, 273-283.

40. Mullbacher, A.; Lobigs, M. Up-regulation of MHC class I by flavivirus-induced peptide translocation into the endoplasmic reticulum. Immunity 1995, 3, 207-214.

41. Cheng, Y.; King, N.J.; Kesson, A.M. Major histocompatibility complex class I (MHC-I) induction by West Nile virus: Involvement of 2 signaling pathways in MHC-I up-regulation. J. Infect. Dis. 2004, 189, 658-668.

42. Larena, M.; Regner, M.; Lobigs, M. Cytolytic effector pathways and IFN-gamma help protect against Japanese encephalitis. Eur. J. Immunol. 2013, 43, 1789-1798.

43. Biron, C.A.; Nguyen, K.B.; Pien, G.C. Innate immune responses to LCMV infections: Natural killer cells and cytokines. Curr. Top. Microbiol. Immunol. 2002, 263, 7-27.

44. Sivori, S.; Falco, M.; Della Chiesa, M.; Carlomagno, S.; Vitale, M.; Moretta, L.; Moretta, A. CpG and double-stranded RNA trigger human NK cells by Toll-like receptors: Induction of cytokine release and cytotoxicity against tumors and dendritic cells. Proc. Natl. Acad. Sci. USA 2004, 101, 10116-10121.

45. Vivier, E.; Nunes, J.A.; Vely, F. Natural killer cell signaling pathways. Science 2004, 306, 1517-1519.

46. Hershkovitz, O.; Rosental, B.; Rosenberg, L.A.; Navarro-Sanchez, M.E.; Jivov, S.; Zilka, A.; Gershoni-Yahalom, O.; Brient-Litzler, E.; Bedouelle, H.; Ho, J.W.; et al. NKp44 receptor mediates interaction of the envelope glycoproteins from the West Nile and dengue viruses with NK cells. J. Immunol. 2009, 183, 2610-2621.

47. Hayday, A.C. Gammadelta cells: A right time and a right place for a conserved third way of protection. Annu. Rev. Immunol. 2000, 18, 975-1026.

48. Wang, L.; Kamath, A.; Das, H.; Li, L.; Bukowski, J.F. Antibacterial effect of human V gamma $2 \mathrm{~V}$ delta 2 T cells in vivo. J. Clin. Invest. 2001, 108, 1349-1357.

49. Ferrick, D.A.; King, D.P.; Jackson, K.A.; Braun, R.K.; Tam, S.; Hyde, D.M.; Beaman, B.L. Intraepithelial gamma delta T lymphocytes: Sentinel cells at mucosal barriers. Springer Semin. Immunopathol. 2000, 22, 283-296.

50. O’Brien, R.L.; Roark, C.L.; Born, W.K. IL-17-producing gammadelta T cells. Eur. J. Immunol. 2009, 39, 662-666.

51. Heilig, J.S.; Tonegawa, S. Diversity of murine gamma genes and expression in fetal and adult T lymphocytes. Nature 1986, 322, 836-840.

52. Huber, S.A.; Graveline, D.; Newell, M.K.; Born, W.K.; O’Brien, R.L. V gamma 1+ T cells suppress and $\mathrm{V}$ gamma 4+ $\mathrm{T}$ cells promote susceptibility to coxsackievirus B3-induced myocarditis in mice. J. Immunol. 2000, 165, 4174-4181.

53. Ninomiya, T.; Takimoto, H.; Matsuzaki, G.; Hamano, S.; Yoshida, H.; Yoshikai, Y.; Kimura, G.; Nomoto, K. Vgamma1+ gammadelta T cells play protective roles at an early phase of murine cytomegalovirus infection through production of interferon-gamma. Immunology 2000, 99, 187-194.

54. Wang, T.; Scully, E.; Yin, Z.; Kim, J.H.; Wang, S.; Yan, J.; Mamula, M.; Anderson, J.F.; Craft, J.; Fikrig, E. IFN-gamma-producing gammadelta T cells help control murine West Nile virus infection. J. Immunol. 2003, 171, 2524-2531. 
55. Shrestha, B.; Wang, T.; Samuel, M.A.; Whitby, K.; Craft, J.; Fikrig, E.; Diamond, M.S. Gamma interferon plays a crucial early antiviral role in protection against West Nile virus infection. J. Virol. 2006, 80, 5338-5348.

56. Welte, T.; Lamb, J.; Anderson, J.F.; Born, W.K.; O’Brien, R.L.; Wang, T. Role of two distinct gammadelta $\mathrm{T}$ cell subsets during West Nile virus infection. FEMS Immunol. Med. Microbiol. 2008, 53, 275-283.

57. Sciammas, R.; Kodukula, P.; Tang, Q.; Hendricks, R.L.; Bluestone, J.A. T cell receptor gammadelta cells protect mice from herpes simplex virus type 1-induced lethal encephalitis. J. Exp. Med. 1997, 185, 1969-1975.

58. Selin, L.K.; Santolucito, P.A.; Pinto, A.K.; Szomolanyi-Tsuda, E.; Welsh, R.M. Innate immunity to viruses: Control of vaccinia virus infection by gamma delta T cells. J. Immunol. 2001, 166, 6784-6794.

59. Tseng, C.T.; Klimpel, G.R. Binding of the hepatitis C virus envelope protein E2 to CD81 inhibits natural killer cell functions. J. Exp. Med. 2002, 195, 43-49.

60. Kesson, A.M.; Blanden, R.V.; Mullbacher, A. The primary in vivo murine cytotoxic T cell response to the flavivirus, West Nile. J. Gen. Virol. 1987, 68, 2001-2006.

61. Brien, J.D.; Uhrlaub, J.L.; Nikolich-Zugich, J. West Nile virus-specific CD4 T cells exhibit direct antiviral cytokine secretion and cytotoxicity and are sufficient for antiviral protection. J. Immunol. 2008, 181, 8568-8575.

62. Welte, T.; Wang, T. University of Texas Medical Branch, Galveston, TX, USA. Unpublished work, 2013.

63. Wang, T.; Gao, Y.; Scully, E.; Davis, C.T.; Anderson, J.F.; Welte, T.; Ledizet, M.; Koski, R.; Madri, J.A.; Barrett, A.; et al. Gammadelta T cells facilitate adaptive immunity against West Nile virus infection in mice. J. Immunol. 2006, 177, 1825-1832.

64. Fang, H.; Welte, T.; Zheng, X.; Chang, G.J.; Holbrook, M.R.; Soong, L.; Wang, T. gammadelta T cells promote the maturation of dendritic cells during West Nile virus infection. FEMS Immunol. Med. Microbiol. 2010, 59, 71-80.

65. Wang, T.; Fikrig, E. Immunity to West Nile virus. Curr. Opin. Immunol. 2004, 16, 519-523.

66. Hayes, E.B.; Gubler, D.J. West Nile virus: Epidemiology and clinical features of an emerging epidemic in the United States. Annu. Rev. Med. 2006, 57, 181-194.

67. Brien, J.D.; Uhrlaub, J.L.; Hirsch, A.; Wiley, C.A.; Nikolich-Zugich, J. Key role of T cell defects in age-related vulnerability to West Nile virus. J. Exp. Med. 2009, 206, 2735-2745.

68. Kunzmann, V.; Bauer, E.; Feurle, J.; Weissinger, F.; Tony, H.P.; Wilhelm, M. Stimulation of gammadelta $\mathrm{T}$ cells by aminobisphosphonates and induction of antiplasma cell activity in multiple myeloma. Blood 2000, 96, 384-392.

69. Wilhelm, M.; Kunzmann, V.; Eckstein, S.; Reimer, P.; Weissinger, F.; Ruediger, T.; Tony, H.P. Gammadelta $\mathrm{T}$ cells for immune therapy of patients with lymphoid malignancies. Blood 2003, 102, 200-206.

70. Wang, S.; Welte, T.; Fang, H.; Chang, G.J.; Born, W.K.; O’Brien, R.L.; Sun, B.; Fujii, H.; Kosuna, K.; Wang, T. Oral administration of active hexose correlated compound enhances host resistance to West Nile encephalitis in mice. J. Nutr. 2009, 139, 598-602. 
71. Welte, T.; Aronson, J.; Gong, B.; Rachamallu, A.; Mendell, N.; Tesh, R.; Paessler, S.; Born, W.K.; O’Brien, R.L.; Wang, T. Vgamma4+ T cells regulate host immune response to West Nile virus infection. FEMS Immunol. Med. Microbiol. 2011, 63, 183-192.

72. Wang, T.; Town, T.; Alexopoulou, L.; Anderson, J.F.; Fikrig, E.; Flavell, R.A. Toll-like receptor 3 mediates West Nile virus entry into the brain causing lethal encephalitis. Nat. Med. 2004, 10, 1366-1373.

73. Weaver, C.T.; Hatton, R.D.; Mangan, P.R.; Harrington, L.E. IL-17 family cytokines and the expanding diversity of effector T cell lineages. Annu. Rev. Immunol. 2007, 25, 821-852.

74. DiTirro, J.; Rhoades, E.R.; Roberts, A.D.; Burke, J.M.; Mukasa, A.; Cooper, A.M.; Frank, A.A.; Born, W.K.; Orme, I.M. Disruption of the cellular inflammatory response to Listeria monocytogenes infection in mice with disruptions in targeted genes. Infect. Immun. 1998, 66, 2284-2289.

75. Bai, F.; Town, T.; Qian, F.; Wang, P.; Kamanaka, M.; Connolly, T.M.; Gate, D.; Montgomery, R.R.; Flavell, R.A.; Fikrig, E. IL-10 signaling blockade controls murine West Nile virus infection. PLoS Pathog. 2009, 5, e1000610.

76. Schneider, B.S.; McGee, C.E.; Jordan, J.M.; Stevenson, H.L.; Soong, L.; Higgs, S. Prior exposure to uninfected mosquitoes enhances mortality in naturally-transmitted West Nile virus infection. PLoS One 2007, 2, e1171.

77. Hahn, Y.S.; Ji, X.Y.; Woo, S.I.; Choi, Y.K.; Song, M.S.; Shin, K.S.; Jin, N.; O’Brien, R.L.; Born, W.K. Vgamma1+ gammadelta $\mathrm{T}$ cells reduce IL-10-producing CD4+CD25+ $\mathrm{T}$ cells in the lung of ovalbumin-sensitized and challenged mice. Immunol. Lett. 2008, 121, 87-92.

78. O’Brien, R.L.; Yin, X.; Huber, S.A.; Ikuta, K.; Born, W.K. Depletion of a gamma delta T cell subset can increase host resistance to a bacterial infection. J. Immunol. 2000, 165, 6472-6479.

79. Born, W.K.; O’Brien, R.L. Antigen-restricted gammadelta T-cell receptors? Arch. Immunol. Ther. Exp. 2009, 57, 129-135.

80. Iwasaki, A.; Medzhitov, R. Toll-like receptor control of the adaptive immune responses. Nat. Immunol. 2004, 5, 987-995.

81. Akira, S.; Hemmi, H. Recognition of pathogen-associated molecular patterns by TLR family. Immunol. Lett. 2003, 85, 85-95.

82. Beetz, S.; Marischen, L.; Kabelitz, D.; Wesch, D. Human gamma delta T cells: Candidates for the development of immunotherapeutic strategies. Immunol. Res. 2007, 37, 97-111.

83. Beetz, S.; Wesch, D.; Marischen, L.; Welte, S.; Oberg, H.H.; Kabelitz, D. Innate immune functions of human gammadelta T cells. Immunobiology 2008, 213, 173-182.

84. Shimura, H.; Nitahara, A.; Ito, A.; Tomiyama, K.; Ito, M.; Kawai, K. Up-regulation of cell surface Toll-like receptor 4-MD2 expression on dendritic epidermal $\mathrm{T}$ cells after the emigration from epidermis during cutaneous inflammation. J. Dermatol. Sci. 2005, 37, 101-110.

85. Peng, G.; Wang, H.Y.; Peng, W.; Kiniwa, Y.; Seo, K.H.; Wang, R.F. Tumor-infiltrating gammadelta $\mathrm{T}$ cells suppress $\mathrm{T}$ and dendritic cell function via mechanisms controlled by a unique toll-like receptor signaling pathway. Immunity 2007, 27, 334-348.

86. Town, T.; Bai, F.; Wang, T.; Kaplan, A.T.; Qian, F.; Montgomery, R.R.; Anderson, J.F.; Flavell, R.A.; Fikrig, E. Toll-like receptor 7 mitigates lethal West Nile encephalitis via interleukin 23-dependent immune cell infiltration and homing. Immunity 2009, 30, 242-253. 
87. Daffis, S.; Samuel, M.A.; Suthar, M.S.; Gale, M., Jr.; Diamond, M.S. Toll-like receptor 3 has a protective role against West Nile virus infection. J. Virol. 2008, 82, 10349-10358.

88. Welte, T.; Reagan, K.; Fang, H.; Machain-Williams, C.; Zheng, X.; Mendell, N.; Chang, G.J.; Wu, P.; Blair, C.D.; Wang, T. Toll-like receptor 7-induced immune response to cutaneous West Nile virus infection. J. Gen. Virol. 2009, 90, 2660-2668.

89. Szretter, K.J.; Daffis, S.; Patel, J.; Suthar, M.S.; Klein, R.S.; Gale, M., Jr.; Diamond, M.S. The innate immune adaptor molecule MyD88 restricts West Nile virus replication and spread in neurons of the central nervous system. J. Virol. 2010, 84, 12125-12138.

90. Zhang, J.; Wang, J.; Xie, G.; Wang, T. University of Texas Medical Branch, Galveston, TX, USA. Unpublished work, 2013.

91. Pietschmann, K.; Beetz, S.; Welte, S.; Martens, I.; Gruen, J.; Oberg, H.H.; Wesch, D.; Kabelitz, D. Toll-like receptor expression and function in subsets of human gammadelta $\mathrm{T}$ lymphocytes. Scand. J. Immunol. 2009, 70, 245-255.

92. Wesch, D.; Beetz, S.; Oberg, H.H.; Marget, M.; Krengel, K.; Kabelitz, D. Direct costimulatory effect of TLR3 ligand poly(I:C) on human gamma delta T lymphocytes. J. Immunol. 2006, 176, 1348-1354.

93. Kunzmann, V.; Kretzschmar, E.; Herrmann, T.; Wilhelm, M. Polyinosinic-polycytidylic acid-mediated stimulation of human gammadelta $\mathrm{T}$ cells via CD11c dendritic cell-derived type I interferons. Immunology 2004, 112, 369-377.

94. Devilder, M.C.; Allain, S.; Dousset, C.; Bonneville, M.; Scotet, E. Early triggering of exclusive IFN-gamma responses of human Vgamma9Vdelta2 $\mathrm{T}$ cells by TLR-activated myeloid and plasmacytoid dendritic cells. J. Immunol. 2009, 183, 3625-3633.

(C) 2013 by the authors; licensee MDPI, Basel, Switzerland. This article is an open access article distributed under the terms and conditions of the Creative Commons Attribution license (http://creativecommons.org/licenses/by/3.0/). 